\title{
Taxonomias tecnológicas e setoriais da indústria de transformação brasileira
}

\author{
Mabel Diz Marques* (D) \\ José Eduardo Roselino** (iD) \\ Suelene Mascarini ${ }^{* * *}$ (ID)
}

* Universidade Federal da Bahia (UFBA), Salvador (BA), Brasil. E-mail: mabeldizmarques@ gmail.com

** Universidade Federal de São Carlos (UFSCar), São Carlos (SP), Brasil. E-mail: jeroselino@ ufscar.br

*** Universidade Federal de São Carlos (UFSCar), São Carlos (SP), Brasil. E-mail: smascarini@ gmail.com

\section{Resumo}

Este artigo discute a aderência de taxonomias industriais de tradição evolucionária à realidade da indústria de transformação brasileira a partir da seleção de indicadores de atividades inovativas para o ano de 2014. Os dados são analisados por meio da técnica de agrupamento, com utilização de 30 indicadores reunidos em sete diferentes grupos de características das atividades inovativas. Parte-se da suposição de que a adequação dessas classificaçóes à realidade brasileira se justifica como um problema de pesquisa relevante, uma vez que essas taxonomias foram originalmente concebidas com base em estruturas produtivas de economias desenvolvidas, requerendo adaptaçóes e qualificaçóes no contexto de uma economia periférica como a brasileira, também marcada por especificidades setoriais. Os resultados sugerem relativa aderência aos padróes internacionais no período analisado, com discrepâncias pontuais em alguns setores.

Palavras-Chave | Taxonomia industrial; Intensidade tecnológica; Análise de cluster

Código-JEL | O3 


\title{
Technological and sectoral taxonomies of the Brazilian manufacturing industry
}

\begin{abstract}
This article discusses the adherence of the industrial taxonomies of evolutionary tradition to the Brazilian transformation industry from the selection of indicators of innovative activities for the year 2014. The data are analyzed with cluster analysis, using thirty indicators gathered in seven different groups of characteristics of innovative activities. It is considered that the adequacy of these classifications to the Brazilian industrial structure is justified as a relevant research topic, since these taxonomies were originally conceived based on developed economies, requiring adaptations to the framework of a peripheral economy such as Brazilian, also characterized by sectoral specificities. The results suggest a relative adherence to international standards in the time period analyzed, with occasional discrepancies in a few sectors.
\end{abstract}

KeYwords: Industry taxonomy; Technological intensity; Cluster analysis

Jel Code | O3 


\section{Introdução}

A partir de esforços voltados para a identificaçáo de padróes setoriais de inovação tecnológica, foram construídas taxonomias industriais que buscam agregar atividades e setores, conforme determinados critérios de agrupamento e análise. A taxonomia setorial proposta por Pavitt (1984) e a classificação tecnológica da Organização para a Cooperação e Desenvolvimento Econômico (OCDE, 2011) são as mais empregadas e difundidas por formuladores de políticas e por pesquisadores da área de economia da inovação, o que possibilita comparaçóes entre países e atividades econômicas, segundo Cavalcante (2014).

A taxonomia de Pavitt (1984) descreve padróes setoriais de inovação originalmente identificados com base em informações sobre empresas do Reino Unido, buscando identificar setores tipicamente associados a três categorias: dominados pelos fornecedores; produção intensiva (intensivos em escala e fornecedores especializados); e baseados em ciência, conforme suas trajetórias tecnológicas setoriais.

Já a classificação tecnológica da OCDE (2011), registrada por Hatzichronoglou (1997), corresponde a uma agregação setorial da indústria de transformação por intensidade tecnológica. As atividades são categorizadas em quartis denominados alta, média-alta, média-baixa e baixa intensidade tecnológica, em função da relação dos gastos em Pesquisa e Desenvolvimento (P\&D) sobre a receita líquida de vendas.

Apesar do marco e relevância da taxonomia de Pavitt (1984) e da classificação OCDE (2011) para o tema, há um grande desafio em classificar setores diante dos fenômenos evolucionários e das especificidades nacionais. De Marchi, Napolitano e Taccini (1996), assim como Archibugi, Cesaratto e Sirilli (1991), testaram modelos para as trajetórias tecnológicas da indústria manufatureira da Itália, baseados na taxonomia de Pavitt (1984) e, apesar de os resultados encontrados não demonstrarem inconsistência, concluíram pela necessidade de testes empíricos para o emprego de taxonomias às diferentes configuraçóes nacionais.

Adicionalmente, como a taxonomia de Pavitt (1984) e a classificaçáo OCDE (2011) foram originalmente desenvolvidas com base em estruturas produtivas de economias desenvolvidas, a adequação do emprego destas às análises voltadas para economias em desenvolvimento - como é o caso brasileiro - é questionada.

Estudos prévios buscaram compreender o padrão setorial de inovação tecnológica da indústria brasileira, identificando fatores que explicam as possíveis diferenças em comparação ao padrão internacional. Dentre os argumentos que fundamentam a pertinência desse tipo de investigação, sobressaem aqueles relacionados aos efeitos 
estruturais das diferentes especializaçóes produtivas e diversas formas de inserção na divisão internacional do trabalho, que certamente refletem nas disparidades de intensidade tecnológica setorial entre os países e no interior da economia (FURTADO; CARVALHO, 2005).

No Brasil, esforços têm sido realizados para identificar o padrão setorial de inovaçâo (FURTADO; CARVALHO, 2005; CAMPOS; URRACA-RUIZ, 2009; GUIDOLIN; MARTINELLI, 2008; CASTRO, 2010; SILVA; HASENCLEVER, 2014; SILVA; SUZIGAN, 2014). Entretanto, parte desses estudos esbarrou na escassez de dados desagregados ao nível setorial trabalhado por Pavitt (1984). Além disso, como mesmo ressalta Pavitt (1984), a alocação de indústrias em uma determinada categoria não é estática e pode evoluir de um padrão para outro, (re)criando ao longo do tempo a necessidade de estudos empíricos da dinâmica tecnológica.

É nesse contexto que o presente estudo se insere, ao investigar o padrão de atividade inovativa e sua aderência à taxonomia de Pavitt (1984) e da OCDE (2011) para a indústria de transformação brasileira, a partir dos mais recentes indicadores disponíveis de sete diferentes características relacionadas aos padróes de inovação, sendo elas: esforços inovativos (internos e externos); equilíbrio entre inovação de produto e processo; taxa de inovação; tamanho; trajetórias tecnológicas; e produtividade. Assim, a partir de um conjunto de indicadores, esse estudo procura identificar as características tecnológicas e o padrão de inovação da indústria de transformação brasileira em 2014, comparando com as principais taxonomias empregadas na literatura.

A principal contribuição do trabalho é, portanto, o esforço de síntese e integração das variáveis de medidas e a associação das classificaçôes setoriais com as classificaçôes tecnológicas, a partir dos dados da Pintec (Pesquisa de Inovação) e PIA-Empresa (Pesquisa Industrial Anual).

Além dessa introdução, o artigo está organizado em mais três seçóes e as consideraçôes finais. A seguir, busca-se recuperar e sintetizar a construção das taxonomias industriais empregadas como referências neste estudo (PAVITT, 1984; OCDE, (2011), a partir da identificação de características conceituais, metodológicas e operacionais. Posteriormente, são descritos os procedimentos metodológicos, por meio da análise de agrupamento (clusters analysis) - técnica estatística multivariada -e discutidos os resultados obtidos. Por fim, apresentam-se as consideraçóes finais, com a menção às limitaçóes e sugestóes para futuras pesquisas pertinentes ao tema. 


\section{Taxonomias e classificações setoriais: uma revisão teórico- metodológico}

No campo da economia da inovação surgiram diversas propostas de taxonomias baseadas em indicadores de esforços tecnológicos, com o intuito de explicar os diferentes padróes setoriais e sintetizar características da estrutura produtiva a partir de um número relativamente reduzido de categoriais (CAVALCANTE, 2014). Fundamentados, sobretudo, pela teoria evolucionária, ou comumente denominados neoschumpeterianos, os estudos desta linha teórica procuram identificar as diferenças intersetoriais na forma de buscar, introduzir, utilizar e difundir inovaçóes na dinâmica capitalista, ou seja, o padrão tecnológico em que as empresas operam (DOSI, 1982, 1988; NELSON; WINTER, 1982; PAVITT, 1984; ROBSON; TOWNSEND; PAVITT, 1988).

Pavitt (1984), com base em um conjunto de indicadores, descreve e explica os padrôes setoriais de mudanças técnicas, a partir das semelhanças e diferenças entre os setores, ao classificar as empresas conforme as competências e trajetórias tecnológicas, considerando que mudanças tecnológicas seriam processos dinâmicos e cumulativos. $\mathrm{O}$ autor propóe três categorias dos setores industriais: dominados pelos fornecedores; produção intensiva (fornecedores especializados e intensivos em escala); e baseados em ciência (GUIDOLIN; MARTINELLI, 2008; CARLIN; CHEVARRIA, 2012).

A categoria setorial dominados pelos fornecedores caracteriza-se por baixos gastos com P\&D. Os aprimoramentos são, em sua maioria, incrementais, as empresas são relativamente pequenas e a cumulatividade e apropriabilidade tecnológicas são limitadas. Segundo Arend (2009), as inovaçôes das empresas desta categoria são predominantemente inovaçóes em processo, incorporadas em equipamentos de capital e insumos intermediários originados em firmas de outros setores, cuja atividade principal é fornecer bens de produção a setores tradicionais.

As empresas classificadas como produçäo intensiva dividem-se em duas categorias. A primeira é a de fornecedores especializados ou difusores do progresso técnico, em que as inovaçóes têm como principal característica a inserção em vários outros setores como insumos de capital. As firmas são geralmente pequenas e localizadas próximas aos usuários, os conhecimentos são especializados e tácitos, além de existir elevada oportunidade e apropriabilidade tecnológica. Na categoria de intensivos em escala, as inovaçóes estáo voltadas tanto para processos quanto para produtos, sendo que a incidência das inovaçóes incrementais (normalmente direcionadas a processo) 
são mais propícias a ocorrer do que inovaçóes radicais em produto. As atividades produtivas envolvem sistemas complexos dominados com maestria.

Já em setores baseados em ciência, as inovaçôes relacionam-se à criação de novos paradigmas tecnológicos viabilizados pelo avanço técnico-científico. As oportunidades tecnológicas são muito elevadas e ocorrem altos dispêndios internos em P\&D (laboratórios formalizados), sendo que uma parcela relevante de seus produtos é insumo para setores de bens de capital e intermediários. Nesse grupo as empresas tendem a ser grandes, com exceçôes de inovadores pequenos e altamente especializados (AREND, 2009).

Além da taxonomia proposta por Pavitt (1984), a classificação da OCDE (2011) é também amplamente difundida nos estudos da economia da inovação. A classificação por intensidade tecnológica da OCDE (2011) é baseada nos processos de produção. Os setores industriais são agregados de acordo com a intensidade tecnológica em quatro grupos: alta, média-alta, média-baixa e baixa (HATZICHRONOGLOU, 1997). ${ }^{1}$

É importante ressaltar que a classificação da OCDE não pressupóe, a priori, nenhum tipo de homogeneidade em cada grupo dos padróes setoriais de mudança técnica, uma vez que os resultados são sensíveis aos níveis de desagregação setorial empregados e também porque as taxonomias são dinâmicas ao longo do tempo.

Nessa linha de abordagem, refinamentos e extensôes da taxonomia proposta por Pavitt (1984) foram realizados com o intuito de analisar os padróes setoriais de inovação. De maneira geral, os resultados demonstram convergência e consistência da taxonomia de Pavitt para países de economias desenvolvidas, tais como os casos italiano (ARCHIBUGI; CESARATTO; SIRILLI, 1991; DE MARCHI; NAPOLITANO; TACCINI, 1996) e espanhol (URRACA-RUIZ, 2000).

O trabalho de Archibugi, Cesaratto e Sirilli (1991) desenvolveu também um esforço para identificar a relação entre estruturas de mercado e desempenho inovativo para a realidade italiana, concluindo que as diferenças intersetoriais seriam mais relevantes do que as diferenças entre tamanhos das empresas na determinação de padróes de atividades inovativas.

Complementarmente, Napolitano (1991) analisou e agrupou em setores a partir do grau de importância dado pelas empresas italianas às fontes de inovação.

1 A revisăo mais recente da classificação OCDE refere à ISIC Rev. 4 publicada em 2016 (GALINDO-RUEGA; VERGER, 2016), na qual incluem-se atividades industriais e năo industriais (agricultura, mineração, serviços públicos, construção e serviços selecionados). As atividades foram agrupadas em cinco categoriais (alta, média-alta, média, média-baixa e baixa intensidade). Apesar dessa última revisão, emprega-se, neste trabalho, a versấo da $\operatorname{OCDE}$ (2011) que foi associada à sistematização das classificaçôes tecnológicas realizada por Cavalcante (2014). 
O autor destaca a existência de distintas fontes de inovação, tais como propostas originadas de funcionários, aquisição de tecnologia, compra de matérias-primas e outros bens intermediários, entre outras, além dos esforços formais associados à $\mathrm{P} \& \mathrm{D}$, que era até entâo o principal, ou mesmo o único, indicador utilizado nos trabalhos voltados ao tema. Conclui-se que as indústrias seguem padróes diferentes para a aquisição de tecnologias. Empresas do setor tradicional apresentam como fonte de inovação mais importante a compra de equipamentos e um papel menor para design. Já empresas de setores tecnologicamente mais sofisticados apontam a P\&D como principal fonte. Por fim, a cooperação com parceiros externos é crucial para as empresas de produção em massa.

No que se refere ainda à identificação das fontes de inovaçóes, merece destaque também o trabalho de Archibugi (1988), que buscou identificar, com base em dados de patentes requeridas por firmas italianas nos EUA, fluxos intersetoriais de capacitaçôes tecnológicas. A autora demonstrou que as empresas, e por consequência seus setores, desenvolvem inovaçôes em áreas tecnológicas diversas, que potencialmente suprem setores distintos.

No âmbito brasileiro, os resultados têm demonstrado relativa aderência da estrutura produtiva aos padróes propostos pela literatura internacional, com exceçôes pontuais de determinados setores (FURTADO; CARVALHO, 2005; GUIDOLIN; MARTINELLI, 2008; CAMPOS; URRACA-RUIZ, 2009; CASTRO, 2010; YONAMINI, 2011; SILVA; SUZIGAN, 2014).

Campos e Urraca-Ruiz (2009), a partir dos dados da Pintec-2000 e PIA-2000, analisam cinco traços da inovação tecnológica industrial (fontes de inovação; formas de conhecimento e aprendizagem; foco da trajetória tecnológica; tipos de resultados inovativo; características de estrutura e desempenho). Os resultados sugerem convergência com a padronização pavittiana. Contudo, a atividade coque, combustíveis nucleares e álcool, que é enquadrada na categoria intensivos em escala para Pavitt (1984), situa-se na indústria brasileira na categoria dominados pelos fornecedores, com prevalência de inovaçóes de processos de caráter incremental. Além disso, a atividade celulose e outras pastas apresentou perfil de fornecedores especializados, expressando um alinhamento com atividades de maior conteúdo tecnológico, o que pode ser um indicativo de maior sofisticação para essa indústria, uma vez que tal atividade é alocada por Pavitt (1984) como parte do grupo intensivos em escala.

Silva e Suzigan (2014) identificaram o perfil inovativo das empresas nacionais a partir de sete categoriais (estrutura e desempenho; resultados; esforços; fontes de informaçáo; fontes de inovação; interatividade; foco na trajetória tecnológica) 
com base nos dados da Pintec-2008, PIA-2008 e Secretaria do Comércio Exterior (Secex). Os resultados apontam que o padrão setorial de inovação da indústria de transformação brasileira é adequado, em termos gerais, à taxonomia de Pavitt. Por outro lado, os setores couro, celulose, alimentos, bebidas e metalurgia básica apresentam baixa aderência à taxonomia. Além disso, as atividades de produtos de minerais não metálicos e produtos de metal registram baixa densidade tecnológica. Segundo os autores, esses setores se assemelham por aspectos de elevada propensão exportadora e concentração econômica, reduzidos esforços inovativos e baixa taxa de inovação.

No que tange à classificação por intensidade tecnológica, Furtado e Carvalho (2005) sugerem uma classificação alternativa para a indústria de transformação, que eventualmente seja ponto de partida para uma reflexão mais sistemática sobre as características estruturais e diferenciadas das trajetórias tecnológicas de países em desenvolvimento, uma vez que os autores concluem que os esforços tecnológicos empreendidos em setores de alta intensidade tecnológica no Brasil, em termos proporcionais, são relativamente inferiores aos realizados nos países desenvolvidos.

Adicionalmente, Guidolin e Martinelli (2008) e Yonamini (2011) apontam que a indústria brasileira possui regimes tecnológicos diferentes dos definidos para os países desenvolvidos, reforçando a importância de estudos sobre as características de mudança técnica nos países em desenvolvimento.

$\mathrm{O}$ presente trabalho se insere, portanto, em meio a um conjunto de iniciativas voltadas à análise de aspectos tecnológicos e inovativos relativos à indústria de transformação em distintas configuraçóes nacionais. $\mathrm{O}$ enfoque deste e de outros trabalhos na indústria de transformação apoia-se na ideia de que as atividades industriais são as mais dinâmicas da economia, em termos de seus efeitos indutores sobre os níveis de produtividade e progresso técnico do conjunto do sistema produtivo. É importante mencionar, no entanto, que outros trabalhos têm procurado expandir essas classificaçóes para além do âmbito dos setores da indústria de transformação (CASTELLACC, 2007; GALINDO-RUEGA; VERGER, 2016; BOGLIACINO; PIANTA, 2016; MORCEIRO, 2018).

Nesse contexto, observa-se uma multiplicidade de classificações e refinamentos que buscam investigar o padrão dos esforços inovativos da indústria de transformação, por meio da combinaçáo de indicadores de intensidade tecnológica, estruturas de mercado e desempenho, pois os critérios para criar os agrupamentos, ou seja, para demonstrar homogeneidade e heterogeneidade entre as atividades econômicas são diversos e as características tecnológicas dos países se mostram distintas. 
Além disso, é importante ressaltar o desafio das ciências em classificar e adotar padrôes setoriais "rígidos" diante das dinâmicas industriais e fenômenos evolucionários. Dessa forma, faz-se necessária a construção de indicadores que reproduzam novos olhares e indiquem, ao longo do processo, as possibilidades de mensuração dos esforços inovativos e padróes tecnológicos em complemento a indicadores mais tradicionais.

Uma possibilidade explorada nesse trabalho é a consideração de características referentes à natureza e ao conteúdo da força de trabalho, dada a relevância do conhecimento tácito para o processo de geração e difusão de conhecimento, que de alguma forma estão relacionadas com atividades de ciência, tecnologia e inovação (C, T\&I). Outra característica empreendida é a da produtividade, visto que inovaçôes geralmente resultam em ganhos diferenciais às empresas, expressando-se em maior valor gerado por unidade de trabalho empregada (SILVA; SUZIGAN, 2014).

\section{Dados e metodologia}

Para analisar o padrão setorial e de inovação das atividades econômicas da indústria de transformaçáo brasileira em 2014, e sua aderência à taxonomia de Pavitt (1984) e classificaçẫo tecnológica proposta pela OCDE (2011), foi selecionado um conjunto de indicadores relativos a 36 atividades econômicas da indústria de transformação da Classificação Nacional de Atividades Econômicas (CNAE 2.0): 19 atividades desagregadas ao nível de dois dígitos (divisão) e 17 ao nível três dígitos (grupo). ${ }^{2}$

Essas atividades selecionadas são aqui classificadas de acordo com as taxonomias analisadas, conforme as características de intensidade tecnológica da OCDE (2011) (alta, média-alta, média-baixa e baixa tecnologia) e categorias setoriais de Pavitt (1984) (dominados pelos fornecedores, produção intensiva em escala, fornecedores especializados e baseados em ciência), apoiadas pelo enquadramento consolidado por Cavalcante (2014).

A base de dados utilizada nesse trabalho foi construída a partir de um conjunto de dados secundários provenientes da Pesquisa de Inovação (Pintec) e Pesquisa Industrial Anual (PIA-Empresa), ambas realizadas pelo Instituto Brasileiro de Geografia e Estatística (IBGE). O estudo está limitado ao ano de 2014, principalmente, devido à disponibilidade de dados da Pintec, que é a última publicação disponível. No Quadro 1 apresentam-se os indicadores utilizados, medida e fonte de informação.

2 Aponta-se que todas as abordagens setoriais são influenciadas pelo nível de agregaçáo adotado. Nesse trabalho, assim como em Cavalcante (2014), os setores são agregados (dois dígitos) quando existe uma uniformização na classificação tecnológica. Alguns setores mesmo que náo uniformes não puderam ser desagregados devido à inexistência do indicador nesse nível. 
QUADRO 1

Indicadores, variáveis e fontes de informaçóes

\begin{tabular}{|c|c|c|c|}
\hline \multicolumn{2}{|l|}{ Indicadores } & Medidas & \multirow{2}{*}{$\frac{\text { Fontes }}{\text { Pintec }}$} \\
\hline \multirow{4}{*}{$\begin{array}{l}\text { Fonte de esforços } \\
\text { internos de atividade } \\
\text { inovativa }\end{array}$} & PD & $\begin{array}{l}\text { Dispêndios realizados nas atividades inovativas (atividades internas } \\
\text { de Pesquisa e Desenvolvimento) / receita líquida de vendas }\end{array}$ & \\
\hline & Pesq & No de pesquisadores (setor)/pessoal ocupado setorial & Pintec \\
\hline & Tec & No de técnicos (setor)/pessoal ocupado setorial & Pintec \\
\hline & Aux & No de auxiliares (setor)/pessoal ocupado setorial & Pintec \\
\hline \multirow{5}{*}{$\begin{array}{l}\text { Fonte de esforços } \\
\text { externos de atividade } \\
\text { inovativa }\end{array}$} & PDex & $\begin{array}{l}\text { Dispêndios realizados nas atividades inovativas com aquisiçăo } \\
\text { externa de } \mathrm{P} \& \mathrm{D} / \mathrm{RLV}\end{array}$ & Pintec \\
\hline & ConhExt & $\begin{array}{l}\text { Dispêndios realizados nas atividades inovativas com aquisiçăo de } \\
\text { outros conhecimentos externos/RLV }\end{array}$ & Pintec \\
\hline & Soft & $\begin{array}{l}\text { Dispêndios realizados nas atividades inovativas com aquisiçăo de } \\
\text { software/RLV }\end{array}$ & Pintec \\
\hline & Maq & $\begin{array}{l}\text { Dispêndios realizados nas atividades inovativas com aquisiçáo de } \\
\text { máquinas e equipamentos/RLV }\end{array}$ & Pintec \\
\hline & Trein & $\begin{array}{l}\text { Dispêndios realizados nas atividades inovativas com treinamento/ } \\
\text { RLV }\end{array}$ & Pintec \\
\hline $\begin{array}{l}\text { Equilíbrio de } \\
\text { inovação de produto/ } \\
\text { processo }\end{array}$ & Prod_Proc & $\begin{array}{l}\text { Equilíbrio relativo entre inovaçáo de produto e processo no setor; } \\
\mathrm{PP}>1 \text { (produto) e } \mathrm{PP}<1 \text { (processo) }\end{array}$ & Pintec \\
\hline Taxa de inovaçăo & TaxInov & $\begin{array}{l}\text { Empresas que implementaram inovaçáo em relaçáo ao total de } \\
\text { empresas no setor de produto e/ou processo }\end{array}$ & Pintec \\
\hline Tamanho & Tam & $\begin{array}{l}\text { Pessoal ocupado em relaçáo ao número de empresas em } \\
\text { 31/12/2014 }\end{array}$ & Pintec (1) \\
\hline \multirow[t]{2}{*}{ Produtividade } & VTI & $\begin{array}{l}\text { Valor da transformaçáo industrial em relaçáo ao pessoal ocupado } \\
\text { em 31/12/2014 }\end{array}$ & $\begin{array}{l}\text { PIA- } \\
\text { Empresa } \\
(2)\end{array}$ \\
\hline & RLV & Receita líquida de vendas/pessoal ocupado (setorial) & Pintec \\
\hline \multirow{18}{*}{$\begin{array}{l}\text { Foco na trajetória } \\
\text { tecnológica }\end{array}$} & Produto & & \\
\hline & TT1 & Alta relevância na melhoria da qualidade dos produtos & Pintec \\
\hline & $\begin{array}{c}\text { TT2 } \\
\text { Mercado }\end{array}$ & Alta relevância na ampliaçáo da gama de produtos ofertados & Pintec \\
\hline & TT3 & $\begin{array}{l}\text { Alta relevância na manutençáo da participação da empresa no } \\
\text { mercado }\end{array}$ & Pintec \\
\hline & TT4 & $\begin{array}{l}\text { Alta relevância na ampliação da participação da empresa no } \\
\text { mercado }\end{array}$ & Pintec \\
\hline & TT5 & Alta relevância na abertura de mercado & Pintec \\
\hline & Processo & & \\
\hline & TT6 & Alta relevância na importância da capacidade produtiva & Pintec \\
\hline & TT7 & Alta relevância na flexibilidade da produção & Pintec \\
\hline & TT8 & Alta relevância na redução dos custos de produção & Pintec \\
\hline & TT9 & Alta relevância na redução dos custos de trabalho & Pintec \\
\hline & TT10 & Alta relevância na redução do consumo de matéria-prima & Pintec \\
\hline & $\begin{array}{l}\text { TT11 } \\
\text { TT12 }\end{array}$ & $\begin{array}{l}\text { Alta relevância na reduçáo do consumo de energia } \\
\text { Alta relevância na reducáo do consumo de água }\end{array}$ & $\begin{array}{l}\text { Pintec } \\
\text { Pintec }\end{array}$ \\
\hline & \multicolumn{3}{|c|}{ Regulaçáo de impacto e enquadramento } \\
\hline & TT13 & $\begin{array}{l}\text { Alta relevância na reduçáo do impacto ambiental e/ou em aspectos } \\
\text { ligados à saúde e segurança }\end{array}$ & Pintec \\
\hline & TT14 & Alta relevância na redução do impacto ambiental & Pintec \\
\hline & TT15 & $\begin{array}{l}\text { Alta relevância na ampliação do controle de aspectos ligados à } \\
\text { saúde e segurança }\end{array}$ & Pintec \\
\hline & TT16 & Alta relevância no enquadramento em regulaçôes e normas padrão & Pintec \\
\hline
\end{tabular}

Fonte: Elaboraçáo dos autores.

(1) Número de pessoas ocupadas em 31/12/2014, estimado a partir dos dados da amostra da Pesquisa Industrial Anual - Empresa

2014 e da Pesquisa Anual de Serviços.

(2) Para unidades locais das empresas industriais com 30 ou mais pessoas ocupadas. 
Como é possível observar no Quadro 1, foram utilizados 30 indicadores para definir os grupos de atividades inovativas no Brasil em 2014. Esses indicadores representam sete diferentes dimensóes, ou características, das atividades inovativas: fonte de esforços internos de atividade inovativa; fonte de esforços externos de atividade inovativa; equilíbrio entre inovaçáo de produto e processo; taxa de inovação; tamanho; produtividade; e foco das trajetórias tecnológicas. Ressalta-se que caracterizar esses indicadores não significa separá-los para a construção dos grupos de atividades inovativas. Assim, esse trabalho sintetiza e integra um conjunto de indicadores que caracterizam o padráo setorial das atividades no Brasil, notadamente já encontrados, total ou parcialmente, nos trabalhos de Campos e Urraca-Ruiz (2009), Castro (2010) e Silva e Suzigan (2014).

A primeira característica reúne os indicadores de fonte de esforços internos de atividade inovativa. A hipótese que se tem é que atividades com maiores esforços internos são aquelas de mais alta atividade inovativa. Além do indicador tradicional, dispêndio interno em $\mathrm{P} \& \mathrm{D}$, são considerados indicadores relacionados à natureza da força e conteúdo do trabalho ao padrão setorial, tais como a participação de pesquisadores, técnicos e auxiliares com equivalência de dedicação total das empresas que implementaram inovaçóes de produto e/ou processo no total da força de trabalho empreendida no setor em 2014. Incluir esses indicadores é relevante, pois se espera que esses sejam proxies associados, pelo menos em parte, aos esforços internos empreendidos nas atividades de ciência, tecnologia e inovação (C, T\&I) das empresas em complemento ao principal indicador de atividade interna (P\&D).

A segunda característica introduz indicadores de fontes de esforços externos de atividade inovativa, e desempenha papel importante na caracterização de padróes setoriais. A análise combinada desta característica com a primeira (esforços internos) permite a identificação não apenas da intensidade de atividades inovativas, mas também da diferenciação entre a geração e a absorção de insumos inovativos. Assim, indicadores mais altos podem estar associados tanto a mais alta atividade inovativa como a mais baixa, dependendo da relação entre a primeira e a segunda característica. Os indicadores utilizados para esforços externos inovativos referem-se ao dispêndio e à aquisição de $\mathrm{P} \& \mathrm{D}$ externo, outros conhecimentos externos nas atividades inovativas, software, máquinas e equipamentos, bem como treinamento realizado por terceiros em relação à receita líquida de venda.

A terceira característica reflete o equilíbrio entre inovação de produto e processo. Espera-se que setores dominados pelos fornecedores e produção intensiva em escala apresentem uma maior participaçáo em termos relativos em inovaçáo de processo, 
bem como setores fornecedores especializados apresentem maior participação de inovação em produto. E, no caso das atividades classificadas como baseados em ciência, supóe-se que haja um equilíbrio entre as significativas ocorrências de inovaçôes de produto e processo (PAVITT, 1984).

A quarta característica é um indicador direto de desempenho, captando o resultado inovativo por meio da taxa de inovação. Setores com maior taxa são aqueles considerados os mais inovativos, como se espera que se enquadrem as atividades classificadas como setores baseados em ciência, seguidos de produção intensiva e dominados pelos fornecedores.

Os aspectos associados às estruturas de mercado são captados a partir do indicador de tamanho médio das empresas, compondo a quinta característica. A relação entre as estruturas de mercado e desempenho inovativo é um tema caro à tradição neoschumpeteriana, ${ }^{3}$ na medida em que remete à existência de diferentes padróes inovativos associados ao próprio desenvolvimento teórico de Schumpeter (1934 e 1943), nos denominados "Marco I" e "Marco II" da obra do autor. Espera-se, por exemplo, que em setores caracterizados por elevados esforços tecnológicos internos em estruturas formais dedicadas à $\mathrm{P} \& \mathrm{D}$, as empresas sejam de grande porte.

A sexta característica, por sua vez, traz medidas de desempenho dos setores em termos do valor gerado por unidade de trabalho. Sáo utilizados dois indicadores de produtividade: o valor da transformação industrial e a receita líquida de vendas, ambos em termos relativos ao pessoal ocupado. Espera-se que atividades intensamente inovativas sejam capazes de transformar oportunidades tecnológicas em ganhos de produtividade, com maiores investimentos em capital humano e capacitaçóes organizacionais. Nesse contexto, cria-se um processo virtuoso em que a ocorrência de inovaçôes e ganhos de produtividade se reforçam mutuamente. Essa relação virtuosa foi identificada por Castellacci (2007), especialmente nos segmentos em que predominam grandes empresas inovadoras em mercados concentrados, aderentes ao "Marco II" schumpeteriano.

Por fim, na sétima característica, estão elencadas 16 medidas, baseadas no trabalho de Silva e Suzigan (2014), nas quais buscam apresentar o indicador foco das trajetórias tecnológicas a partir das informaçóes da alta relevância incorporadas ao setor. Assim, conforme propóe Pavitt (1984), setores baseados em ciência tendem

3 A relação entre as estruturas do mercado e desempenho inovativo das empresas é tema controverso na literatura. Archibugi, Cesaratto e Sirili (1991) criticam a perspectiva mais convencional de economia industrial, associada ao paradigma "estrutura, conduta e desempenho", por considerarem que o desempenho das firmas (inovativo inclusive) seria condicionado pela estrutura de mercado vigente, num sentido unidirecional de causalidade. Essa abordagem, além de não atentar para características específicas dos setores, não se preocuparia em explicar como as estruturas são formadas. 
a indicar alta relevância em qualquer indicador de trajetória. Já setores dominados pelos fornecedores podem apresentar maior relevância nos indicadores TT6 a TT12 (processo). Setores intensivos em escala indicariam como altamente relevantes os indicadores TT3 a TT12 (mercado e processo) e setores fornecedores especializados são os que assinalam alta relevância nos indicadores TT1 a TT5 (produto e mercado).

Em vista do exposto e com o objetivo de identificar o padrão setorial de inovação tecnológica da indústria de transformação brasileira em 2014, a partir de um conjunto de indicadores de sete diferentes características, este trabalho faz uso da análise de cluster.

A análise de cluster é uma técnica multivariada de classificação que visa agrupar dados por meio das similaridades ou dissimilaridades entre eles (HAIR et al., 2009). Assim, agrupa um conjunto de dados selecionados, seguindo um critério fixado. Essa técnica tem sido bastante utilizada na literatura e envolve uma série de distintos métodos e algoritmos para agrupar objetos/indivíduos do mesmo tipo nas respectivas categorias (JOHNSON, 1967; GONÇALVES; SIMÓES, 2005; FIELDING, 2007; CASTRO, 2010; SILVA, 2013). Portanto, a análise de cluster é uma ferramenta que busca a triagem de diferentes objetos/indivíduos em grupos, de modo que o grau de associação entre dois objetos é máximo, se eles pertencem ao mesmo grupo, e mínimo, em caso contrário. Assim, a análise de cluster não permite explicar porque as estruturas de dados existem, mas sim descobrir como elas ocorrem. Os métodos e algoritmos da análise de cluster são variados e dependem de um conjunto de hipóteses e análises para serem definidos.

Este trabalho utiliza um processo hierárquico a partir das medidas de dissimilaridade representada pela medida de distância. A medida de dissimilaridade escolhida foi a distância Canberra. ${ }^{4}$ Além disso, como método de agrupamento, adotou-se Average Linkage Method (também denominado de método de ligação por média, Group Average ou Unweighted Pair-groups Method Average: UPGMA), no qual emprega-se uma medida central de distância para medir a dissimilaridade. O método de ligação por média permite a representação dos resultados na forma gráfica conhecida por dendograma, que será apresentada nos resultados. Ressalta-se que outros métodos e algoritmos foram testados, mas esse foi o que mais se adequou ao estudo em questão. Deve-se apontar que, ainda que os indicadores tenham sido

4 A distância Canberra introduzida por Lance e Williams (1966) corresponde à versăo ponderada da distância de Manhattan. Esta é calculada pela soma das diferenças fracionárias entre dois pontos. A equaçăo da distância é definida como: dij $=\mathrm{dist}(\mathrm{Ei}, \mathrm{Ej})$ $\sum_{k=1}^{p} \frac{\left|x_{i k}-x_{j k}\right|}{\left|x_{i k}\right|+\left|x_{i k}\right|}$ em que: dij = distância Canberra entre os casos i e j; xik (xjk) = atributo do i-ésimo (j-ésimo) componente na k-ésima variável; $\mathrm{p}$ = números de variáveis. 
separados em sete características nesse trabalho, a análise de cluster foi aplicada a todos os indicadores conjuntamente.

Antes de apresentar os resultados, aponta-se que, ao aplicar a técnica hierárquica de agrupamento aglomerativo por meio da distância Canberra e utilizar o método de ligação por média (Average Linkage Method), o coeficiente de correlação cofenética $(\mathrm{ccc})^{5}$ encontrado foi de 0,71335 , que valida o elevado grau de ajuste à matriz de dissimilaridade com o dendograma.

Realizados os agrupamentos, os indicadores serão apresentados em cada grupo e individualmente para cada atividade de análise em questáo.

\section{Resultados e discussão}

As 36 atividades econômicas foram separadas em quatro grupos, sendo possível identificar o ponto de corte na distância 20, valor que corresponde a $83 \%$ da distância máxima observada nos níveis de fusão (Figura 1). Dada a utilização do método aglomerativo, os casos mais similares são fundidos mais próximos da base e os mais dissimilares ao longo do dendograma. Já na Tabela 1 são apresentadas cada cluster e suas atividades com seus respectivos indicadores.

Quatro são os agrupamentos formados a partir da análise de cluster realizada. O primeiro, nomeado de setores de média-alta atividade inovativalfornecedores especializados (Figura 1 e Tabela 1), é composto por três atividades econômicas: "27 (exclusive 27.1+27.3+23.5) - máquinas elétricas"; “32.5 - instrumentos médicos”; e "29.4 - peças", que representam $8,3 \%$ das atividades selecionadas. Este agrupamento apresenta, em geral, indicadores de esforços internos, externos, equilíbrio entre inovação de produção e processo, taxa de inovação, trajetórias tecnológicas e tamanho acima ou igual à média da indústria de transformação, com exceção dos indicadores de produtividade que estão abaixo da média da indústria de transformação. Além disso, quando comparado aos outros clusters, é o grupo que apresenta os maiores indicadores selecionados, ficando abaixo apenas do cluster $I V$ como, por exemplo, indicador Pesq: 1,0 para cluster $I$ e Pesq: 3,1 para cluster $I V$.

5 O cálculo do coeficiente ccc resulta em um valor entre 0 (zero) e 1 (um). Assim, o menor grau de distorção é refletido pelo maior coeficiente (ccc), sendo este capaz de evidenciar corretamente a melhor estrutura dos dados e formaçáo do dendograma. De acordo com Rohlf (1970), ccc superior a 0,7 indica adequabilidade do grau de ajuste do método de agrupamento para resumir as informaçôes do conjunto de dados. 
Taxonomias tecnológicas e setoriais da indústria de transformação brasileira
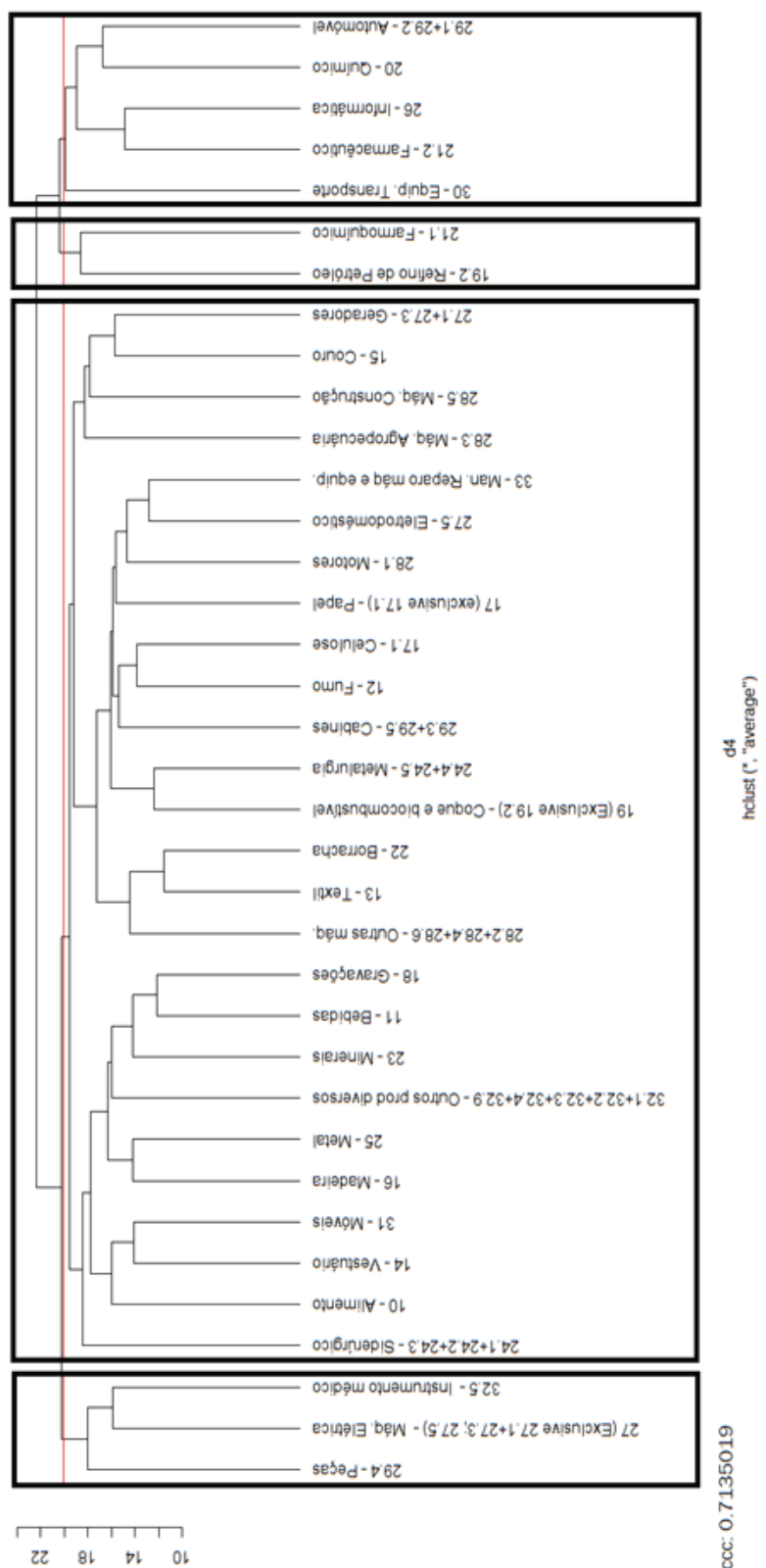

วิ66|วН 


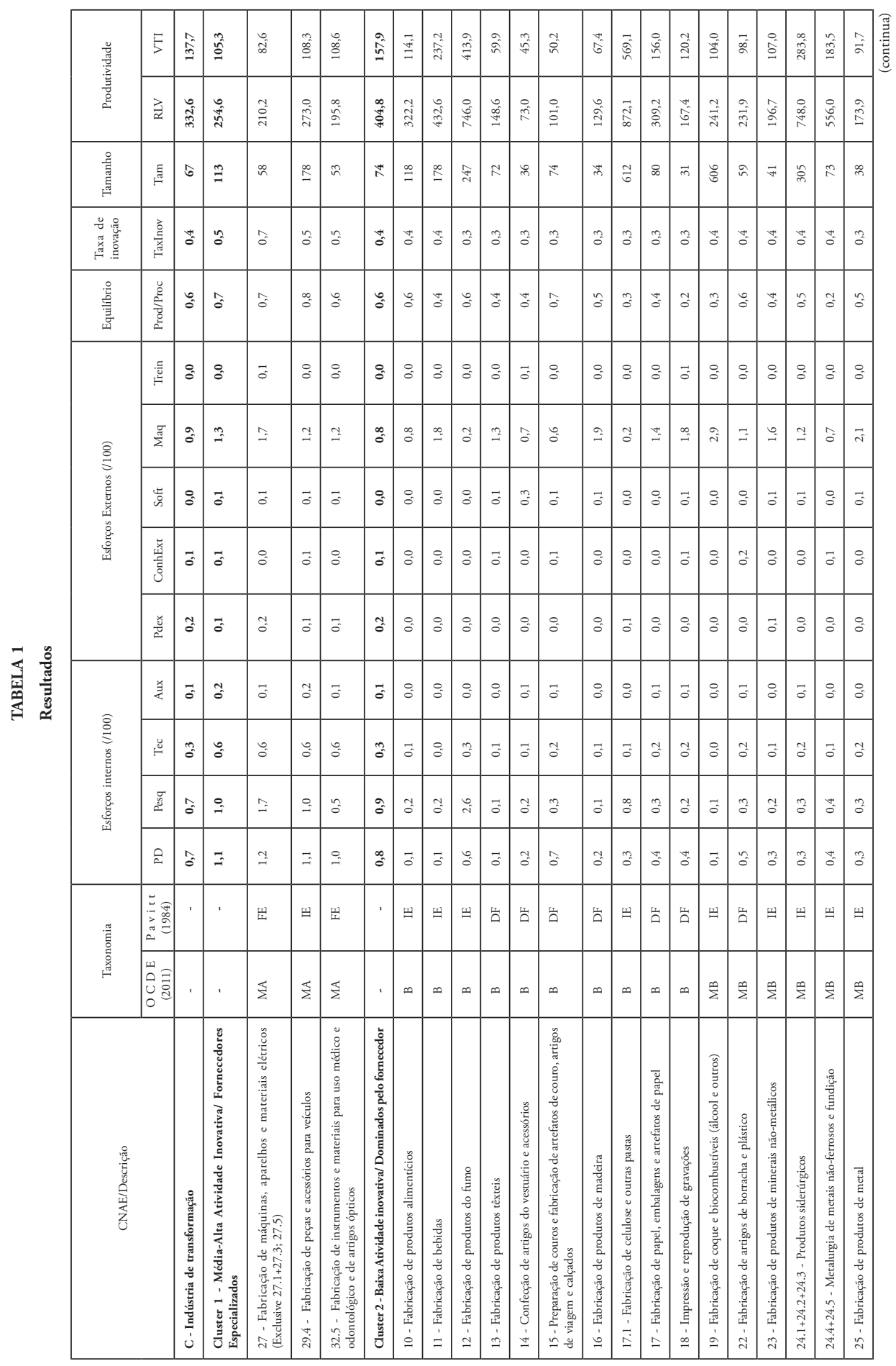




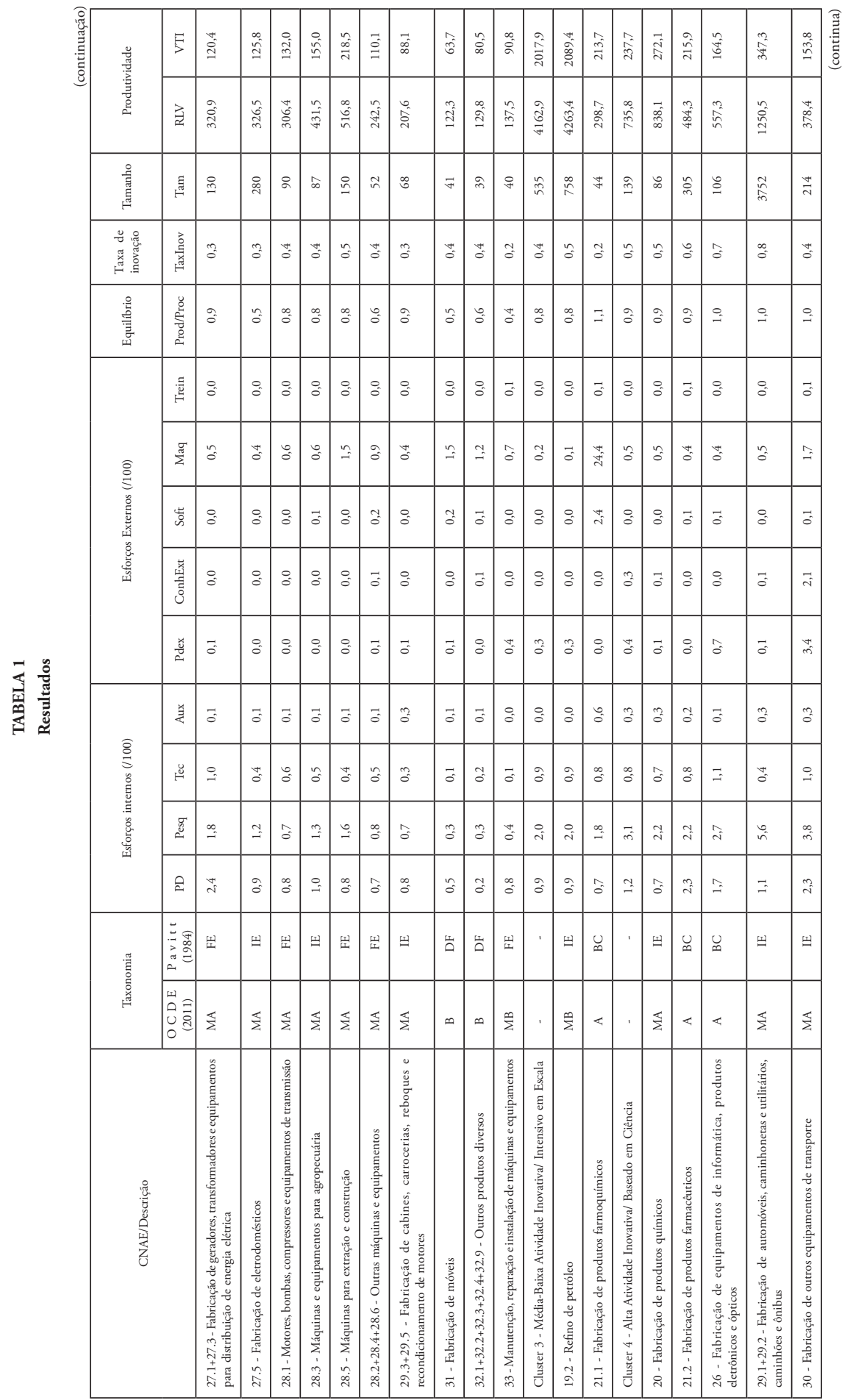




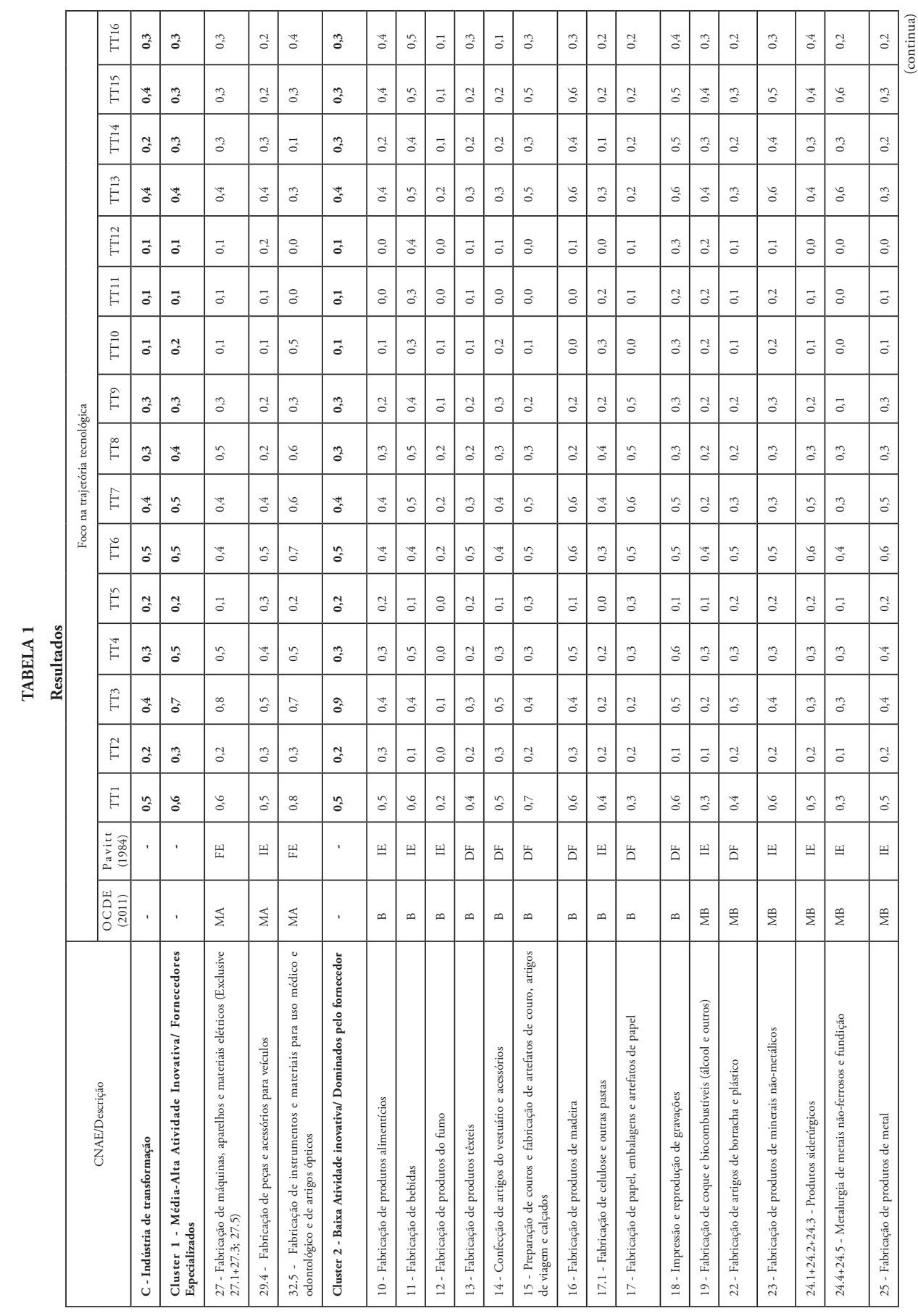




\begin{tabular}{|c|c|c|c|c|c|c|c|c|c|c|c|c|c|c|c|c|c|c|c|c|c|}
\hline \multirow{2}{*}{ 兽 } & \multirow{16}{*}{ 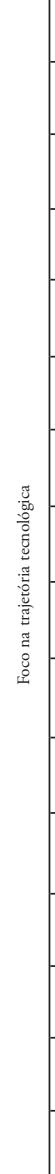 } & 3 & בै & $\overrightarrow{0}$ & 3 & : & 3 & व̃ & 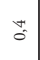 & 范 & $=$ & $0_{0}^{*}$ & za & $3_{0}^{3}$ & 蒙 & st & $\because$ & to & : & $m_{0}^{2}$ & $\frac{\pi}{\Sigma}$ \\
\hline & & 3 & 깅 & 今̃ & 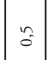 & $3^{2}$ & 3 & वै & : & $a$ & 3 & $:$ & $\because$ & na & 3 & 3 & $3_{0}^{2}$ & $H_{0}^{*}$ & $\stackrel{*}{0}$ & ${ }_{0}^{2}$ & \\
\hline \multirow{17}{*}{ 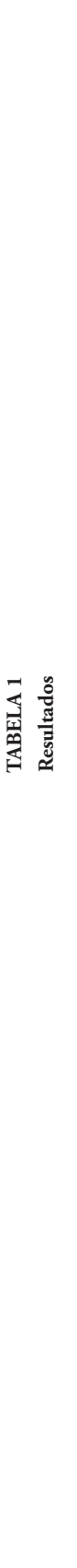 } & & $\stackrel{m}{0}$ & $\because$ & 今ै & $\begin{array}{l}z \\
0\end{array}$ & $\overrightarrow{0}$ & है & no & $\begin{array}{l}7 \\
0 \\
0\end{array}$ & $\because$ & å & 3 & 3 & $\hat{o}$ & $0^{2}$ & $3_{0}^{2}$ & $\overrightarrow{0}$ & בI & $\stackrel{0}{0}$ & to & \\
\hline & & tr & 3 & $\stackrel{y}{0}$ & $\because$ & 范 & 3 & s & : & $a$ & 3 & $: 1$ & ${ }_{0}^{\circ}$ & $\because$ & $\begin{array}{ll}* \\
0\end{array}$ & : & $3_{0}^{2}$ & $u_{0}^{\prime \prime}$ & $a$ & $n$ & \\
\hline & & $\because$ & $\overrightarrow{0}$ & $\begin{array}{l}3 \\
0\end{array}$ & $\because$ & $\therefore$ & $\overrightarrow{0}$ & : & $\therefore$ & $\because$ & $\therefore$ & $\overrightarrow{0}$ & $\overrightarrow{0}$ & $\therefore$ & $\overrightarrow{0}$ & $=$ & $=$ & $\overrightarrow{0}$ & $=$ & $=$ & \\
\hline & & $\overrightarrow{0}$ & $\overrightarrow{0}$ & $\overrightarrow{0}$ & $\overrightarrow{0}$ & $\overrightarrow{0}$ & $\overrightarrow{0}$ & त् & $=0$ & $\because$ & $\therefore$ & $\therefore$ & $\therefore$ & $\therefore$ & $=0$ & $\overrightarrow{0}$ & वै & ב̃ & $\stackrel{1}{0}$ & $\overrightarrow{0}$ & \\
\hline & & $\overrightarrow{0}$ & $\overrightarrow{0}$ & $\overrightarrow{0}$ & $=$ & $\overrightarrow{0}$ & $\overrightarrow{0}$ & 3 & ב3 & 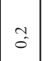 & $\therefore$ & $=$ & $\therefore$ & $=$ & $=$ & $=$ & $=0$ & $\overrightarrow{0}$ & 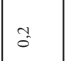 & ב & \\
\hline & & $\because$ & $\overrightarrow{0}$ & $\because$ & $\because$ & בี & $\because$ & : & $3_{0}^{2}$ & $3_{0}^{2}$ & $\begin{array}{ll}2 \\
0\end{array}$ & $=1$ & $\overrightarrow{0}$ & $\therefore$ & 3 & $\stackrel{\simeq}{0}$ & $3^{3}$ & $3_{3}^{3}$ & $\because$ & $\because$ & \\
\hline & & : & $\overrightarrow{0}$ & $\begin{array}{l}3 \\
0\end{array}$ & $\overrightarrow{0}$ & ב & 足 & $\overrightarrow{0}$ & $3^{2}$ & 3 & 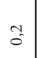 & $=$ & $\overrightarrow{0}$ & $\therefore$ & 3 & 3 & $3^{3}$ & $3_{0}^{3}$ & $\therefore$ & $m_{3}^{2}$ & \\
\hline & & 范 & $\overrightarrow{0}$ & $\begin{array}{c}3 \\
0\end{array}$ & 盛 & an & $\stackrel{0}{0}$ & 3 & 范 & 范 & $\overrightarrow{0}$ & $3_{0}^{2}$ & 3 & $\overrightarrow{0}$ & 3 & 3 & ${ }_{0}^{2}$ & to & a & $\therefore$ & \\
\hline & & $a$ & 㕝 & $\stackrel{3}{0}$ & 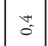 & : & 盀 & $\stackrel{7}{0}$ & 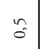 & $\because$ & $8^{2}$ & $3^{2}$ & 范 & $\stackrel{7}{0}$ & $0_{0}^{*}$ & $\stackrel{4}{0}$ & $\stackrel{0}{0}$ & to & ${ }^{n}$ & 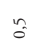 & \\
\hline & & $I_{0}^{\prime}$ & $z_{0}^{2}$ & 3 & 年 & ב⿱ & 今. & בz & $3^{2}$ & : & $\therefore$ & 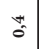 & 范 & a & 3 & 3 & ב् & : & $\stackrel{+r}{0}$ & ? & \\
\hline & & $3_{3}^{2}$ & $3_{0}^{3}$ & $\begin{array}{l}0 \\
0\end{array}$ & $\tilde{O}$ & ב⿱ & 3 & $\overrightarrow{0}$ & 3 & : & $3^{2}$ & $:$ & 3 & 范 & 0 & $\because$ & so & a & $3_{0}^{3}$ & $a$ & \\
\hline & & a & $3_{3}^{2}$ & $\hat{o}$ & $\begin{array}{ll}n \\
0\end{array}$ & $3_{3}^{2}$ & $\ddot{0}$ & ב̊ & 3 & : & $\overrightarrow{0}$ & $\hat{0}$ & $\hat{0}$ & $\stackrel{0}{\circ}$ & $\hat{0}$ & $a$ & $\stackrel{0}{0}_{0}$ & $\therefore$ & 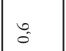 & $n$ & \\
\hline & & 范 & $\stackrel{2}{2}$ & $\stackrel{9}{0}$ & $3^{2}$ & $3^{3}$ & 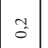 & శ̊ & $3_{3}^{2}$ & $3^{3}$ & $\overrightarrow{0}$ & 3 & 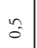 & $\stackrel{0}{\circ}$ & 3 & 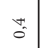 & of & ב̃ & s & to & \\
\hline & & $\begin{array}{l}0 \\
0 \\
0\end{array}$ & : & $\hat{0}$ & 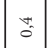 & 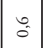 & an & 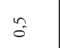 & $\because$ & $\because$ & $\overrightarrow{0}$ & $\hat{0}$ & 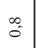 & $\because$ & $\stackrel{0}{\circ}$ & $\because$ & $\therefore$ & ó & $\stackrel{\infty}{0}$ & $\hat{0}$ & \\
\hline & 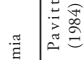 & 㟧 & $\Phi$ & 岀 & 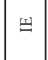 & 圆 & 出 & $\underline{\mu}$ & 岂 & 㟔 & 亗 & ' & 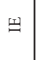 & O & ' & 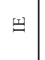 & $\stackrel{u}{\mathscr{D}}$ & $u_{\circledast}$ & $\Leftrightarrow$ & $\mu$ & \\
\hline & 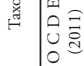 & 量 & $\frac{\pi}{2}$ & $\frac{s}{2}$ & $\frac{\pi}{2}$ & $\frac{5}{2}$ & $\frac{5}{2}$ & $\frac{\pi}{2}$ & $\infty$ & $\infty$ & $\stackrel{\rho}{\Sigma}$ & ' & $\frac{\rho}{2}$ & $<$ & . & $\frac{s}{2}$ & $<$ & $\varangle$ & $\frac{5}{2}$ & $\frac{\pi}{2}$ & \\
\hline & 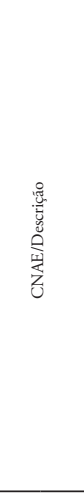 & 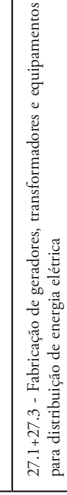 & 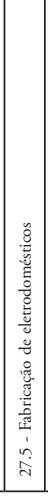 & 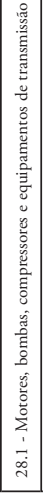 & 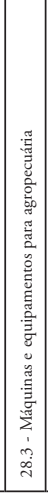 & 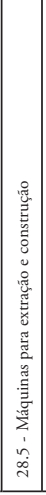 & 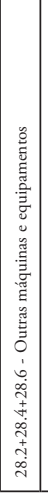 & 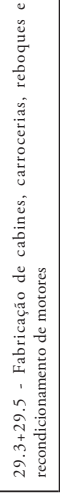 & 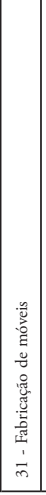 & 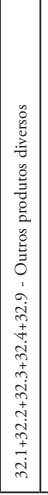 & 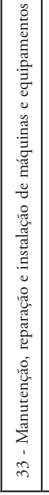 & 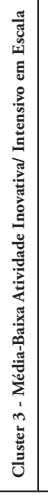 & 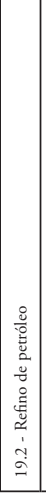 & 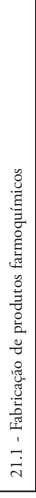 & 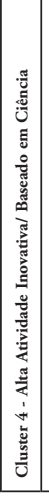 & 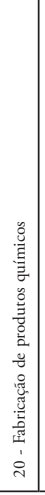 & 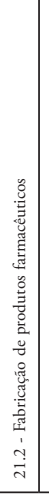 & 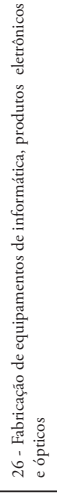 & 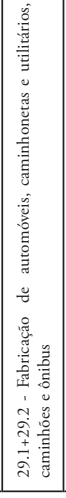 & 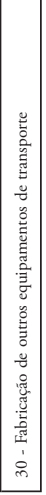 & 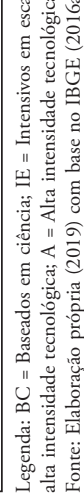 \\
\hline
\end{tabular}


Quatro são os agrupamentos formados a partir da análise de cluster realizada. O primeiro, nomeado de setores de média-alta atividade inovativalfornecedores especializados (Figura 1 e Tabela 1), é composto por três atividades econômicas: "27 (exclusive 27.1+27.3+23.5) - máquinas elétricas"; “32.5 - instrumentos médicos”; e " 29.4 - peças", que representam $8,3 \%$ das atividades selecionadas. Este agrupamento apresenta, em geral, indicadores de esforços internos, externos, equilíbrio entre inovação de produção e processo, taxa de inovação, trajetórias tecnológicas e tamanho acima ou igual à média da indústria de transformação, com exceção dos indicadores de produtividade que estão abaixo da média da indústria de transformação. Além disso, quando comparado aos outros clusters, é o grupo que apresenta os maiores indicadores selecionados, ficando abaixo apenas do cluster $I V$ como, por exemplo, indicador Pesq: 1,0 para cluster $I$ e Pesq: 3,1 para cluster $I V$.

Já o segundo cluster, nomeado como setores de baixa atividade inovatival dominados por fornecedores (Tabela 1) engloba $72,2 \%$ das atividades selecionadas (Figura 1), sendo elas: "10 - alimento; 11 - bebida; 12 - fumo; 13 - têxtil; 14 vestuário; 15 - couro; 16 - madeira; 17 (exclusive 17.1) - papel; 17.1 - celulose; 18 - gravaçóes; 19 (exclusive 19.2) - coque e biocombustível; 22 - borracha; 23 - minerais; $24.1+24.2+24.3$ - siderúrgico; $24.4+24.5$ - metalurgia; 25 - metal; 27.1+27.3 - geradores; 27.5 - eletrodoméstico; 28.1 motores; 28.3 - máq. agropecuária; 28.5 - máq. construção; 28.2+28.4+28.6 - outras máq.; 29.3+29.5 - cabines; 31 - móveis; $32.1+32.2+32.3+32.4+32.9$ - outros prod. diversos; 33 man. reparo maq. e equip.”. Esse agrupamento apresenta indicadores bem próximos à média da indústria de transformação brasileira, ademais, detém os mais baixos indicadores médios de atividade inovativa interna (PD: 0,78; Pesq.: 0,91 e Tec.: $\mathbf{0 , 3 4 )}$, esforços inovativos externos próximos à média nacional, com predominância de inovaçôes de processo incorporada em suas atividades produtivas (Prod_Proc: 0,6), firmas de pequeno porte (Tam: 74), com baixa taxa inovativa (TaxInov: 0,38) e produtividade (RLV: 404,8 e VTI: 157,9). Ao comparar esses indicadores com os dos outros clusters, esse grupamento também apresenta os menores desempenhos. Esse resultado demonstra o quão frágil são as atividades inovativas no Brasil, uma vez que mais de $70 \%$ das atividades apresentam um padrão de baixa intensidade tecnológica e dominados pelos fornecedores. Esses dados estão em consonância com a fragilidade das atividades tecnológicas e inovativas da indústria brasileira, identificada por Melo, Fucidji e Possas (2015). 
O terceiro cluster, denominado como média-baixa atividade inovativa/intensivo em escala (Figura 1 e Tabela 1), é composto por duas atividades industriais (19.2 refino de petróleo e 21.1 - indústria de produtos farmoquímicos), que em conjunto representam 5,5\% das atividades selecionadas. Este agrupamento exibe esforços inovativos bem próximos à média da indústria de transformação (relativamente superiores em termos de esforços internos e levemente inferiores no que tange aos esforços externos) e incidência tanto de inovaçóes de produtos como de processos, embora as de processos sejam mais significativas. As trajetórias tecnológicas são focalizadas na melhoria da qualidade dos produtos, manutenção da participação da empresa no mercado e redução do impacto ambiental e/ou em aspectos ligados à saúde e segurança. Além disso, este agrupamento exibe indicadores acima dos apresentados no cluster II.

Já o quarto e último cluster, nomeado como alta atividade inovativalbaseados em ciência, é formado por 13,8\% das atividades selecionas, sendo elas: "20 - químico; 21.2 - farmacêutico; 29.1+29.2 - fabricação de automóvel; 30 - fabricação de outros equipamentos de transporte". Em geral, nesse agrupamento estáo os maiores indicadores quando comparado aos outros clusters, exibindo desempenho superior à média da indústria de transformação. Além disso, ressalta-se a ocorrência do mais elevado indicador de esforço inovativo interno, especialmente, em termos de intensidade de P\&D (PD: 1,2) e alocaçáo de pesquisadores nas atividades internas de $\mathrm{P} \& \mathrm{D}$, com equivalência de dedicação total das empresas que implementaram inovaçóes de produto e/ou processo em relaçáo ao pessoal ocupado do setor (Pesq: 3,1). Outro destaque pode ser dado ao indicador de equilíbrio entre produto e processo, por demonstrar relativo equilíbrio, o que sugere que inovaçóes tanto de produto como de processo estão sendo geradas em volumes próximos, resultado convergente a setores baseados em ciência. Entretanto, diferentemente do esperado com base nas principais taxonomias, que indicariam a predominância de empresas de grande porte, os resultados encontrados apontam estruturas empresariais caracterizada por porte médio (TAM: 139).

Posto isto, é possível analisar as atividades que compóem os grupos formados e sua convergência com as principais taxonomias internacionais e trabalhos anteriores realizados para o Brasil, sendo estes expostos no Quadro 2. 


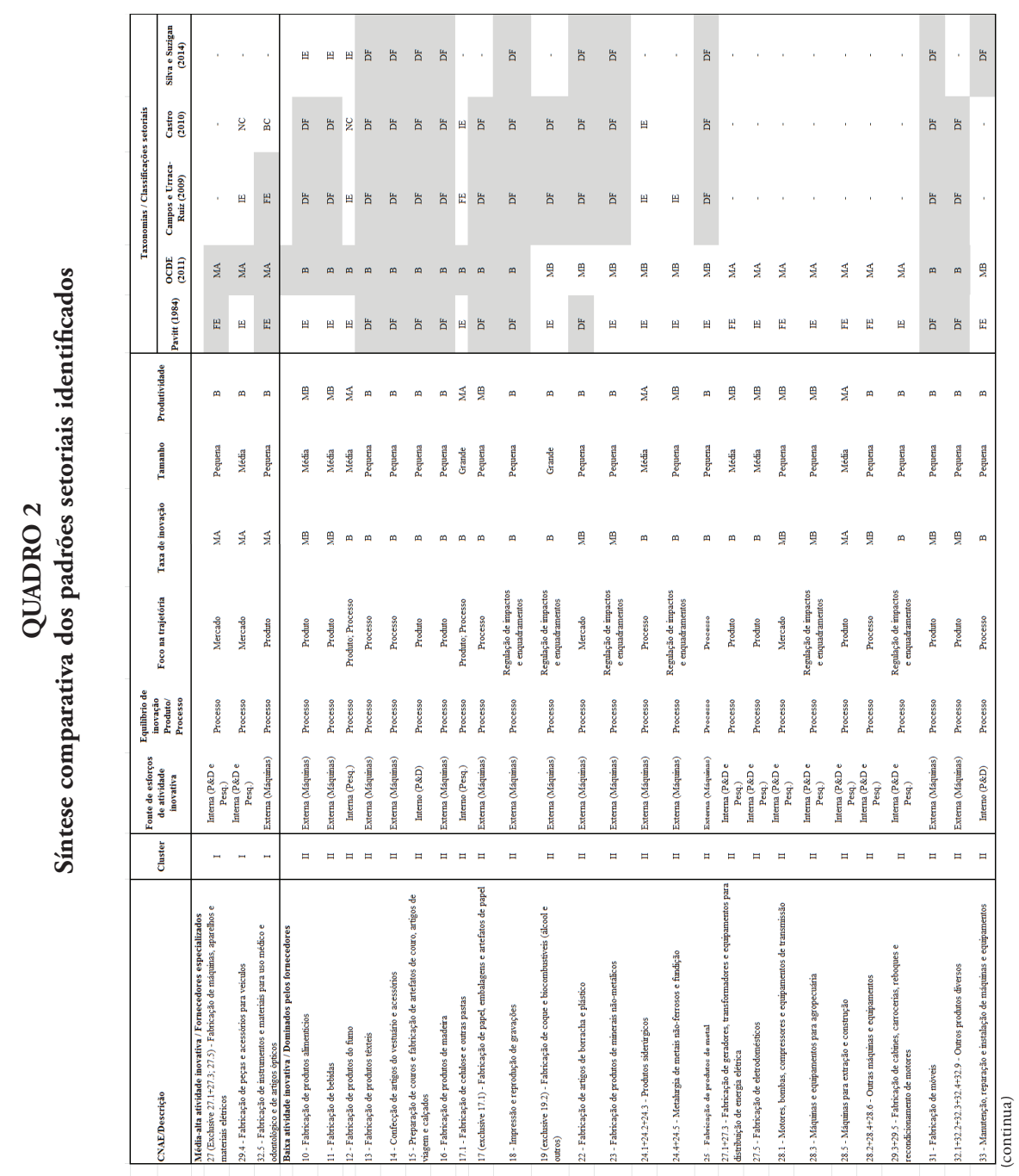


Taxonomias tecnológicas e setoriais da indústria de transformação brasileira

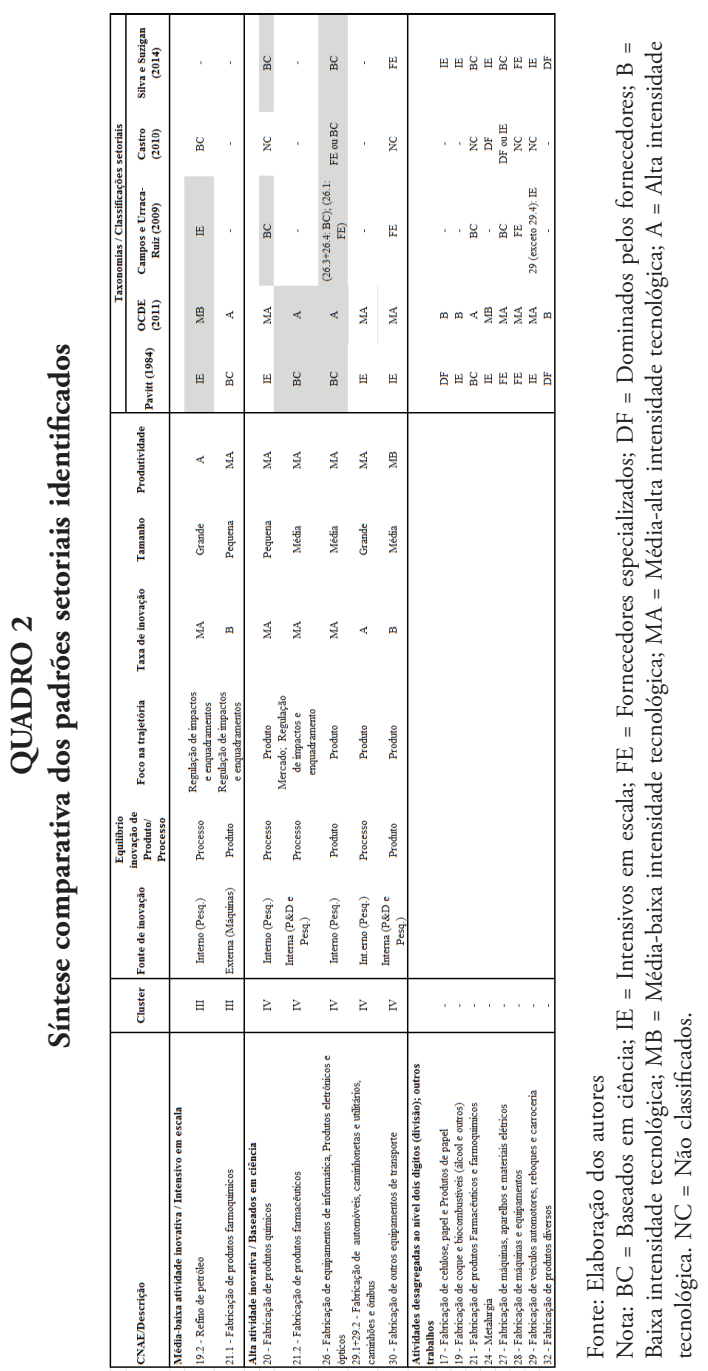


Como apontado anteriormente, os indicadores do cluster I sugerem que este é formado por setores de média-alta atividade inovativalfornecedor especializado. Ao analisar as atividades inerentes a este cluster, é possível apontar que as atividades 27 (exclusive $27.1+27.3+27.5)$ e 32.5 exibem relativa aderência tanto à taxonomia de Pavitt (1984) quanto da OCDE (2011), diferindo apenas em relação ao indicador de equilíbrio, no qual se esperava que fosse concentrada em produtos, mas exibe inovaçóes concentradas em processos. Ademais, o enquadramento da atividade 32.5 é convergente ao encontrado por Campos e Urraca-Ruiz (2009).

O cluster II é caracterizado por apresentar atividades de baixa atividade inovativaldominados pelos fornecedores. De modo geral, os setores são convergentes aos encontrados tanto pelas classificaçôes internacionais (PAVITT, 1984; OCDE, 2011) como de alguns estudos já realizados para o Brasil (CAMPOS; URRACA-RUIZ, 2009; CASTRO, 2010; SILVA; SUZIGAN, 2014). Estes são os casos das atividades 13, 14, 15, 16, 17 (exclusive 17.1), 18, 31 e $32.1+32.2+32.3+32.4+32.9$. Por outro lado, houve pouca aderência dos setores de produção intensiva (que incluem intensivos em escala e fornecedores especializados), segundo taxonomia proposta por Pavitt (1984), à realidade da indústria de transformaçáo brasileira a partir dos indicadores selecionados, uma vez que estes são alocados no presente trabalho como dominados pelos fornecedores. Ademais, algumas atividades de média alta intensidade tecnológica segundo classificação da $\operatorname{OCDE}$ (2011), tais como 27.5, 28.1, 28.5 e $28.2+28.4+28.6$, diferem dos resultados encontrados neste estudo (baixa intensidade). Quanto aos estudos realizados para o Brasil, não foi possível comparar estes setores, uma vez que tais atividades foram analisadas ao nível de dois dígitos (divisão).

Três hipóteses explicativas são levantadas em relação a estes resultados. A primeira é a de que o padrão setorial de inovação no Brasil apresenta uma estrutura diferente dos preconizados pelas principais taxonomias e reflete a fragilidade da nossa indústria em termos inovativos. Já a segunda hipótese está relacionada à existência de mudanças estruturais que possam ter ocorrido nessas atividades, visto que este trabalho faz uso dos indicadores mais atuais de atividade inovativa no Brasil. Por fim, a terceira hipótese relaciona-se aos indicadores adicionados e sua utilização conjunta para agrupamento, visto que alocaçáo no grupo dessas atividades pode estar relacionada à inclusão de indicadores de mão de obra e produtividade que são importantes para caracterizar as atividades inovativas.

Além disso, os setores 23 e 25 também podem ser destacados por apresentarem estruturas industriais de pequeno porte, resultado que difere do padrão internacional (em que se espera que sejam estruturas de grande porte), entretanto, tal resultado 
é semelhante ao encontrado por Campos e Urraca-Ruiz (2009), Castro (2010) e Silva e Suzigan (2014).

No que se refere ao cluster III, formado por duas atividades, destaque pode ser dado à atividade 21.1, que, embora apresente desempenho acima da média da indústria de transformação, exibe indicadores de P\&D muito aquém ao esperado quando comparados aos padrôes internacionais, colocando-a em uma categoria de média-baixa atividade inovativa, enquanto esta é classificado como de alta atividade tecnológica pela OCDE. Ressalta-se que essa atividade (21.1) em grande parte dos trabalhos anteriores (CAMPOS; URRACA-RUIZ, 2009; SILVA; SUZIGAN, 2014) é analisada de forma conjunta à atividade 21.2, o que pode ter acarretado sua alocação como alta atividade tecnológica de forma (relativamente) equivocada, no caso brasileiro.

Esse argumento é corroborado por Vargas et al. (2010), ao apontarem que as atividades de maior intensidade tecnológica associadas ao processo de $\mathrm{P} \& \mathrm{D}$ e à produção de princípios ativos da indústria de farmoquímicos e farmacêutica tendem a se concentrar em países desenvolvidos, ficando para as filiais alocadas em países menos desenvolvidos, como o caso do Brasil, a produção (formulação) de medicamentos e aplicação de testes clínicos com metodologias desenvolvidas externamente. Sendo assim, em países em desenvolvimento, como Brasil, a avaliação dos padrões setoriais devem buscar distinguir as atividades de farmacêutica (21.1) e farmoquímicos (21.2).

Outra questão a ser destacada no cluster III é a atividade de refino de petróleo (19.2), que, apesar de exibir enquadramento adequado ao esperado com base nas principais classificaçóes analisadas, diverge do resultado encontrado por Castro (2010), ao apontar essa atividade como outlier em termos inovativos, exibindo características de baseados em ciência no caso brasileiro.

Por fim, vale destacar as atividades $20,29.1+29.2$ e 30 inseridas no cluster IV (alta atividade inovativalbaseados em ciência) ao apresentarem características de padrão setorial superior ao apontado nas principais taxonomias, já que são alocadas aqui como baseadas em ciência, quando se esperaria que estivessem enquadradas junto às atividades intensivas em escala.

\section{Considerações finais}

O presente estudo buscou identificar as características tecnológicas mais amplas da indústria de transformação brasileira, que definem a intensidade dos esforços tecnológicos e padróes setoriais de inovaçáo, a partir da integraçáo de indicadores e 
variáveis de caracterização setorial selecionados na Pintec e PIA-Empresa para 2014. Ademais, procurou-se sistematizar os resultados aqui encontrados comparando-os com as principais taxonomias industriais associadas à tradição evolucionária de Pavitt (1984) e OCDE (2011), bem como classificaçóes voltadas ao caso brasileiro, tais como Campos e Urraca-Ruiz (2009), Castro (2010) e Silva e Suzigan (2014).

O trabalho foi desenvolvido com base em dois eixos: teórico e metodológico/ empírico. Do ponto de vista teórico, o trabalho fundamentou-se no arcabouço teórico neoschumpeteriano, para revisar e discutir a construção das principais taxonomias industriais a partir de suas características conceituais, metodológicas e operacionais.

Do ponto de vista metodológico/empírico, foram construídos 30 indicadores, agregados em sete diferentes dimensóes, sendo estes provenientes da base de dados da Pintec e PIA-Empresa para 2014. Para tanto, empregou-se a análise multivariada (cluster analysis) por meio da técnica hierárquica de agrupamento aglomerativo, uso da distância Canberra e método de ligação por média (Average Linkage Method) para identificar e caracterizar os padróes setoriais de inovação e esforços tecnológicos.

Em termos gerais, observou-se que um expressivo contingente de setores da indústria de transformação enquadra-se em categorias de baixa atividade inovativa e dominados pelos fornecedores no Brasil. Todas as atividades ora identificadas como dominados pelos fornecedores foram convergentes com os resultados encontrados por Pavitt (1984), Campos e Urraca-Ruiz (2009), Castro (2010) e Silva e Suzigan (2014). Acontece que este cenário foi agravado pela incorporação de atividades com características de produção intensiva (escala e fornecedores especializados) e média alta atividade tecnológica neste grupo (cluster II).

Já nas atividades agrupadas nos clusters I (média alta atividade inovativa/ fornecedor especializado) e IV (alta atividade inovativa/baseados em ciência) foram incorporadas, de uma forma mais ampla, as atividades difusoras do progresso técnico, que exibem elevada oportunidade e apropriabilidade tecnológica. Observou-se também importância expressiva da fonte de tecnologia interna, proveniente sobretudo de pesquisadores incorporados aos setores e dispêndio realizados nas atividades inovativas (atividades internas de P\&D).

Além disso, é preciso observar que, no cluster II, foram agrupados setores que exibem características de inovação e esforços tecnológicos abaixo do padrão identificado por Pavitt (1984) e a OCDE (2011), especialmente aqueles associados à categoria de produção intensiva e média-alta atividade inovativa.

Por fim, resta-nos fazer algumas consideraçóes a respeito do cluster III (média-baixa atividade inovativa/intensivo em escala). Os resultados sinalizam que, embora 
tenha ocorrido convergência da atividade refino de petróleo (19.2) com as principais taxonomias e classificaçóes aqui apresentadas, esperava-se que este setor apresentasse maiores esforços inovativos e tecnológicos no contexto brasileiro, uma vez que a cadeia produtiva do petróleo é caracterizada no Brasil por crescente interação com universidades e centros pesquisa com a constituiçâo de redes de colaboraçôes científicas (GIELFI et al, 2017).

Já a atividade 21.1 (fabricação de produtos farmoquímicos), que é considerada pelas classificaçôes internacionais mais relevantes como sendo de alta intensidade tecnológica e baseada em ciência, no caso brasileiro apresenta um padrão setorial de média-baixa atividade inovativa e indicadores selecionados próximos à média da indústria de transformação. Tal resultado não pôde ser comparado aos demais estudos prévios para indústria brasileira, tais como Campos e Urraca-Ruiz (2009), Castro (2010) e Silva e Suzigan (2014) porque, nestes trabalhos, o setor foi tratado de forma agregada à atividade 21.2 (produtos farmacêuticos, que neste trabalho encontram-se no cluster IV), resultando na sua incorporação ao grupo das atividades baseadas em ciência e de alta intensidade tecnológica.

Nesta perspectiva e com base nas exposiçôes anteriores, justifica-se a pertinência da análise dos padrôes tecnológicos e inovativos das economias não centrais, pois os setores industriais apresentam especificidades em termos de complexidades tecnológicas e inovativas e se alteraram ao longo do tempo, exigindo reavaliaçôes periódicas.

Faz-se necessária, portanto, a construção de indicadores que reproduzam novos olhares e que indiquem possibilidades de mensuração dos padróes inovativos em atividades industriais e não industriais, tendo em vista que as classificaçôes setoriais são instrumentos de observação para um conjunto de fenômenos complexos da economia e apoiam o desenho e a implementação de políticas setoriais, bem como a tomada de decisóes sobre uso de recursos públicos.

Por fim, é importante reconhecer algumas limitaçōes dessa pesquisa. A primeira está relacionada aos indicadores referentes às inovaçóes de produto e/ou processo, provenientes da Pintec: a partir desta fonte, inexiste a possibilidade de se identificar com rigor se as inovaçóes foram desenvolvidas no próprio setor e/ou em outros, uma vez que todos os indicadores são associados à atividade principal da empresa. Portanto, esse trabalho assumiu que as inovaçóes foram desenvolvidas e/ou empregadas no setor de atividade principal da empresa. A segunda está relacionada ao fato de que a análise das taxonomias restringe-se à indústria de transformação, não contemplando informaçóes sobre outros setores relevantes. A ampliação da delimitação de âmbito em estudos desse tipo é crescentemente desejável, na medida 
em que outros setores e atividades, como os dos serviços associados às tecnologias de informação e comunicação, conquistam progressivamente maior importância tecnológica e inovativa nas estruturas produtivas.

\section{Agradecimentos}

Coordenação de Aperfeiçoamento de Pessoal de Nível Superior - Capes.

Conselho Nacional de Desenvolvimento Científico e Tecnológico - CNPq.

Fundação de Apoio Institucional ao Desenvolvimento Científico e Tecnológico da Universidade Federal de São Carlos - FAI UFSCar.

\section{Referências bibliográficas}

AREND, M. 50 anos de industrialização do Brasil (1955-2005): uma análise evolucionária. 2009. 252 f Tese (Doutorado em Economia) - Universidade Federal do Rio Grande do Sul, Porto Alegre, 2009.

ARCHIBUGI, D. The inter-industry distribution of technological capabilities. A case study in the application of the Italian patenting in the USA. Technovation, v. 7, n. 3, p. 259-274, 1988.

ARCHIBUGI, D.; CESARATTO, S.; SIRILLI, G. Sources of innovative activities and industrial organization in Italy. Research Policy, v. 20, n. 4, p. 299-313, 1991.

BOGLIACINO, F.; PIANTA, M. The Pavitt taxonomy, revisited: patterns of innovation in manufacturing and services. Economia Política, v. 33, n. 2, p. 153-180, 2016.

CAMPOS, B.; URRACA-RUIZ, A. Padrões setoriais de inovação na indústria brasileira. Revista Brasileira de Inovação, Campinas, v. 8, n. 1, p. 167-210, jan./jun. 2009.

CARLIN, D. O.; CHEVARRIA, D. G. Investigação da relação entre a estrutura de capital e inovação e intensidade tecnológica nas companhias abertas brasileiras: uma análise com base na Taxonomia de Pavitt. In: SIMPÓSIO DE GESTÃO DA INOVAÇÃO TECNOLÓGICA, n. 26, 2012, Salvador. Anais [...]. Salvador/BA: Anpad, 2012. p. 1-15.

CASTELLACCI, F. Technological regimes and sectoral differences in productivity growth. Industrial and Corporate Change, v. 16, n. 6, p. 1105-1145, 2007.

CASTELLACCI, F. Technological paradigms, regimes and trajectories: manufacturing and service industries in a new taxonomy of sectoral patterns of innovation. Research Policy, v. 37, n. 6-7, p. 978-994, 2008. 
CASTRO, D. F. Padróes setoriais da inovação tecnológica na indústria brasileira: uma análise de cluster a partir da PINTEC. 2010. 125 f. Dissertação (Mestrado em Economia Política) - Pontifica Universidade Católica de São Paulo, São Paulo, 2010.

CAVALCANTE, L. R. Classificações tecnológicas: uma sistematização. Brasília: Instituto de Pesquisa Econômica Aplicada (Ipea), 2014 (Nota Técnica Diset, n. 17).

DE MARCHI, M.; NAPOLITANO, G.; TACCINI, P. Testing a model of technological trajectories. Research Policy, v. 25, n. 1, p. 13-23, 1996.

DOSI, G. Technological paradigms and technological trajectories: a suggested interpretation of the determinants and directions of technical change. Research policy, v. 11, n. 3. p. 147$162,1982$.

DOSI, G. et al. The nature of the innovative process. In: DOSI, G.; FREEMAN, C.; NELSON, R. R.; SILVERBERG, G.; SOETE, L. (ed.). Technical change and economic theory. Londres: Pinter Publishers, 1988. p. 590-607.

FIELDING, A. Cluster and classification techniques for the biosciences. Cambridge: Cambridge University Press, 2007.

FURTADO, A. T.; CARVAlHO, R. Q. Padrôes de intensidade tecnológica da indústria brasileira: um estudo comparativo com os países centrais. São Paulo em Perspectiva, São Paulo, v. 19, n. 1, p.70-84, 2005.

GALINDO-RUEDA, F.; VERGER, F. V. OECD taxonomy of economic activities based on $R \& D$ intensity. Paris: OECD Publishing, 2016. (OECD Science, Technology and Industry Working Papers, n. 2016/04).

GIELFI, G. G.; FURTADO, A. T.; CAMPOS, A. S. de; TIJSSEN, R. A interação universidadeempresa na indústria de petróleo brasileira: o caso da Petrobras. Revista Brasileira de Inovação, v. 16, n. 2, p. 325-350, 2017.

GONÇALVES, E.; SIMÓES, R. Padróes de esforço tecnológico da indústria brasileira: uma análise setorial a partir de técnicas multivariadas. Revista Economia, v. 6, n. 2, p. 391-433, 2005.

GUIDOLIN, S. M; MARTINELLI, O. Regimes tecnológicos da indústria brasileira: uma contribuição para a análise empírica. In: ENCONTRO NACIONAL DOS CENTROS NACIONAIS DE PÓS-GRADUAÇÃO EM ECONOMIA, 36, 2008, Salvador. Anais [...].Salvador/BA: Anpec, 2008.

HAIR, J. F.; BLACK, W. C.; BABIN, B. J; ANDERSON, R. E.; TATHAM R. L. Análise multivariada de dados. 6. ed. Porto Alegre: Bookman Editora, 2009. 
HATZICHRONOGLOU, T. Revision of the high-technology sector and product classification. OCDE Science. Paris, 1997. Disponível em: <https://www.oecd.org/sti/ind/48350231. pdf>. Acesso em: 20 ago. 2017.

IBGE - Instituto Brasileiro de Geografia e Estatística. Pesquisa de Inovação 2014. Rio de Janeiro, 2016a.

IBGE - Instituto Brasileiro de Geografia e Estatística. Pesquisa Industrial Anual - Empresa (2014. Rio de Janeiro, 2016b.

JOHNSON, S. C. Hierarchical clustering schemes. Psychometrika, v. 32, n. 3, p. 241-254, 1967.

LANCE, G. N.; WILLIAMS, W. T. Computer programs for hierarchical polythetic classification ("similarity analyses"). The Computer Journal, v. 9, n. 1, p. 60-64, 1966.

MELO, T. M.; FUCIDJI, J. R.; POSSAS, M. L. Política industrial como política de inovação: notas sobre hiato tecnológico, políticas, recursos e atividades inovativas no Brasil. Revista Brasileira de Inovação, Campinas, v. 14, n. esp., p. 11-36, mar. 2015.

MORCEIRO, P. C. A indústria brasileira no limiar do século XXI: uma análise da sua evolução estrutural, comercial e tecnológica. 2018, 198 fTese (Doutorado em Economia) - Faculdade de Economia, Administração e Contabilidade, Universidade de São Paulo, São Paulo, 2018. NAPOLITANO, G. Industrial research and sources of innovation: across-industry analysis of Italian manufacturing firms. Research Policy, v. 20, p.171-178. 1991.

NELSON, R.; WINTER, S. Evolutionary theory of economic change. Cambridge MA: Belknap Press of Harvard University Press, 1982.

OCDE - Organização para a Cooperação e Desenvolvimento Econômico. Science, Technology and Industry Scoreboard. Annex 1: Classification of manufacturing industries based on technology, Paris: OCDE, 2007.

OCDE - Organização para a Cooperação e Desenvolvimento Econômico. ISIC Rev 3. Technology intensity definition. Paris: OCDE, 2011.

PAVITT, K. Sectoral patterns of technical change: towards a taxonomy and a theory. Research Policy, v.13, n. 6, p. 343-373, 1984.

ROBSON, M.; TOWNSEND, J.; PAVITT, K. Sectoral patterns of production and use of innovations in the UK. Research Policy, v. 17, n. 1, p. 1-14, 1988.

ROHLF, F. J. Adaptative hierarquical clustering schemes. Systematic Zoology, v. 19, n. 1, p. 58-82, 1970. 
SCHUMPETER, J. The theory of economic development. Cambridge: Harvard University Press, 1934.

SCHUMPETER, J. Capitalism, socialism and democracy. New York: Harper, 1943.

SILVA, E. H. Sectoral taxonomy with indicators of innovative effort. Revista de Economia Contemporânea, Rio de Janeiro, v. 17, n. 1, p. 129-152, 2013.

SILVA, C. F; SUZIGAN, W. Padrôes setoriais de inovação da indústria de transformação brasileira. Estudos Econômicos, São Paulo, v. 44, n. 2, p. 277-321, 2014.

SILVA, E. H.; HASENCLEVER, L. Regime tecnológico e emergência dos padrôes de estratégias inovativas das firmas. Revista Brasileira de Inovação, Campinas, v. 13, n. 1, p. 45-76, 2014.

URRACA-RUIZ, A. Patrones sectoriales de cambio técnico en la industria española. Economía industrial, n. 332, p. 99-108, 2000.

VARGAS, M. A.; GADELHA, C. A.; MALDONATO, J. M.; BARBOSA, P. R. Reestruturação na indústria farmacêutica mundial e seus impactos na dinâmica produtiva e inovativas do setor farmacêutico brasileiro. In: ENCONTRO NACIONAL DE ECONOMIA POLÍTICA, 15., 2010, São Luiz, MA. Anais [...]. São Luiz, MA: Enep, 2010.

YONAMINI, F. M. Nova taxonomia de regimes tecnológicos para o caso de um país em desenvolvimento como o Brasil. 2011. 109 f Tese (Doutorado em Desenvolvimento Econômico) - Programa de Pós-graduação em Desenvolvimento Econômico, Universidade Federal do Paraná, Curitiba, 2011.

\section{(c) ) EY-NC}

Esta obra foi licenciada sob uma Licença Creative Commons Atribuição-NãoComercial 3.0 Brasil. 
